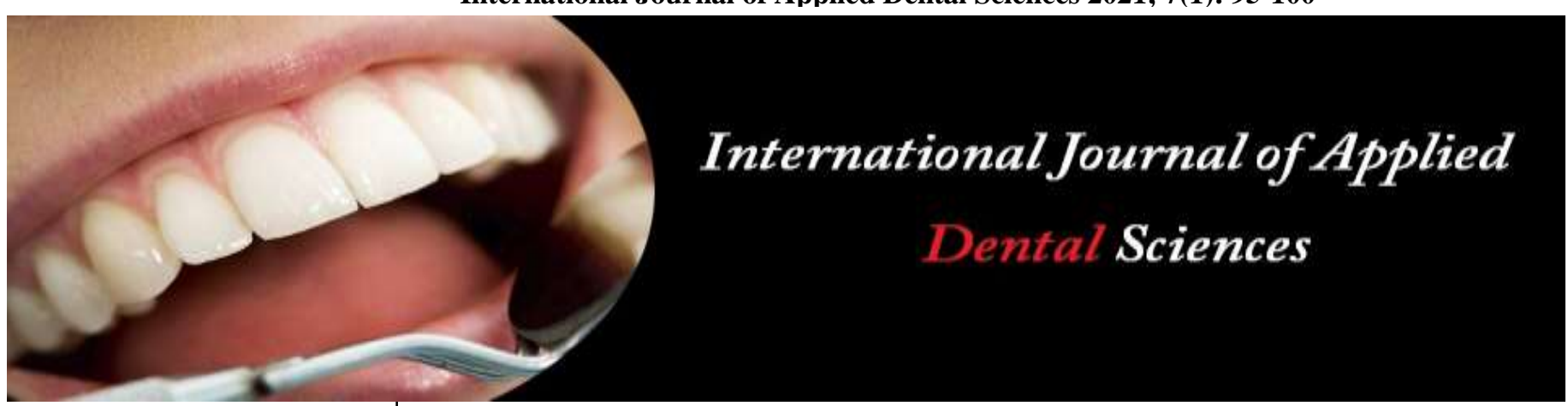

ISSN Print: 2394-7489

ISSN Online: 2394-7497

IJADS 2021; 7(1): 95-100

(C) 2021 IJADS

www.oraljournal.com

Received: 12-11-2020

Accepted: 15-12-2020

Dr. Jignesh Tate

Post Graduate, Yogita Dental

College and Hospital, Khed,

Maharashtra, India

Dr. Varsha Jadhav

Professor and Head of

Department, Yogita Dental

College and Hospital, Khed,

Maharashtra, India

Corresponding Author:

Dr. Jignesh Tate

Post Graduate, Yogita Dental

College and Hospital, Khed,

Maharashtra, India

\section{Combined approach with demineralized bone matrix and platelet concentrates in the treatment of periodontal intra-bony defect: A case report}

\author{
Dr. Jignesh Tate and Dr. Varsha Jadhav
}

DOI: https://doi.org/10.22271/oral.2021.v7.i1b.1122

\section{Abstract}

Periodontitis is a multifactorial disease that leads to destruction of hard and soft tissues. Regenerative periodontal therapy has been proven to be more efficient in restoring these lost tissues, when compared to open flap debridement. Several bone grafts/substitutes have been used for the treatment of intrabony defects. Demineralized freeze-dried bone allograft (DFDBA) has been proven clinically as well as histologically, to be the material of choice for regeneration. Platelet-rich fibrin (PRF), on the other hand has been said to have certain properties that aid in wound healing as well as regeneration. Therefore, this case report aims at evaluating regenerative capacity of PRF when combined with DFDBA.

Keywords: Periodontal Regeneration, Intrabony defects, DFDBA, PRF

\section{Introduction}

Periodontal regeneration is a complex process that requires an organized series of biological events that include cell adhesion, migration, multiplication and differentiation ${ }^{[1]}$. The objective of periodontal regenerative procedures is to restore the periodontal tissues viz. the bone, cementum and periodontal ligament on a diseased root surface ${ }^{[2]}$. The therapeutic end point of bone grafts and growth modulators is that a material or technique must histologically demonstrate that bone, cementum and a functional periodontal ligament (a new attachment apparatus) can be formed on a previously diseased root surface ${ }^{[3]}$. Regenerative potential of platelets was introduced in the 70's ${ }^{[4]}$. It was found that they contain growth factors that are prudent in increasing collagen production, cell mitosis, blood vessels growth, recruitment of other cells that migrate to the site of injury, and cell differentiation induction ${ }^{[5]}$. PRF was introduced by Choukroun et al. in $2001^{[6]}$ and is currently considered as a new generation of platelet concentrate. It consists of a matrix of autologous fibrin ${ }^{[7]}$ and has several advantages over the first-generation platelet concentrate (PRP), which includes easier preparation and not necessitating manipulation of the blood, which makes it stringently an autologous preparation. ${ }^{5}$ Several studies have presented that PRF is a healing biomaterial with a great potential for hard and soft tissue regeneration, and may be used alone or in combination with bone grafts, promoting hemostasis, bone growth, and maturation ${ }^{[8,9,10,11]}$ in vitro studies exhibited a great potential to increase cell adhesion ${ }^{[12]}$ and to stimulate cells to proliferate and differentiate into osteoblasts ${ }^{[13]}$. The purpose of this case report is to understand and discuss a case of intrabony defect in maxillary incisor, treated with combination of PRF and DFDBA bone graft successfully.

\section{Clinical Presentation}

A 32-year old female patient reported to the Dept. of Periodontics, Yogita Dental College and Hospital, Khed; with a chief complaint of deposits on her teeth and pain in upper front tooth region since 1 month. Patient was apparently asymptomatic about a month back after which she started observing deposits on her teeth, followed by pain in upper front tooth region, which was dull aching in nature. Patient reported history of trauma in relation to the region of concern and got root canal treatment done two years back. 
Extraoral examination did not reveal any significant abnormality. Intraoral examination revealed generalized gingival inflammation, accentuated scalloping with thick rolled margins, position of gingival margin apical to CEJ irt. 21 and bleeding on probing was present. Periodontal examination exhibited Grade I mobility, Miller's Calss I recession, Probing Pocket Depth of $11 \mathrm{~mm}$ and Clinical attachment loss of $12 \mathrm{~mm}$. (Fig. 1) Radiographic examination showed vertical defects, extending till apical third of the root irt. 21. (Fig. 2)

\section{Case management}

Patient was taken up for phase-I periodontal therapy which included thorough supragingival and subgingival scaling and root planning. (Fig. 3). Routine blood investigations with complete blood count, bleeding time, clotting time and random blood sugar were also advised to the patient before the surgical intervention.

\section{Surgical Procedure}

After performing all the routine investigations of the patient, Open flap debridement (OFD) of the lesion was performed under local anesthesia ( $2 \%$ lignocaine with adrenaline). A circumoral preparation with povidone iodine was performed to prevent transfer of resident flora to the surgical site. Intraoral disinfection was acheived by using $0.2 \%$ chlorhexidine mouthrinse prior to surgery. Crevicular and papilla preservation incisions were placed irt. 21 and full thickness flap was elevated on buccal and palatad aspect. (Fig. 4, 5) Defect was thouroughly debrided, root planned and scaled with gracey curettes. (Fig. 6) Root biomodification was done using 15\% EDTA. (Fig. 7) After debridement PRF membrane was prepared by centrifuging $10 \mathrm{ml}$ of venous blood at 2700rpm for 12minutes under strict septic conditions. $^{6}$ Out of the three layers obtained after centrifugation, middle layer of platelet rich fibrin was retrieved from the tubes with the help of sterile tweezer. The platelet rich fibrin was placed between gauze pieces drenched in saline and digital pressure was applied. (Fig. 8) PRF was minced and mixed with bone graft to prepare into a transferable mass. (Fig. 9) Barrier membrane (CollaGuide) was adapted along the buccal flap and presuturing was done. (Fig. 10) DFDBA and PRF mixture was placed in the defect and condensed properly. (Fig. 11) Interrupted sutures were placed and surgical site was protected by applying a periodontal dressing (Coe-pak). (Fig. 12) Antibiotics and analgesics prescribed for 5 days. Patient was asked to rinse with $2 \%$ cholorhexidine gluconate mouthrinses for 15 days. Patient was recalled after 7 days, 1 month, 3 months and 6 months for follow up. (Fig. 13) Healing was uneventful with no scarring and post-operative infection. RVG was taken to check the bone fill. (Fig. 14). A bone fill of 50- 60\% was appreciated on RVG with no side effects postoperatively after 6months.

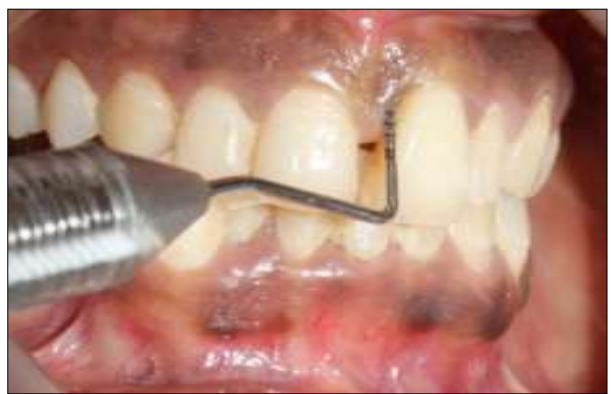

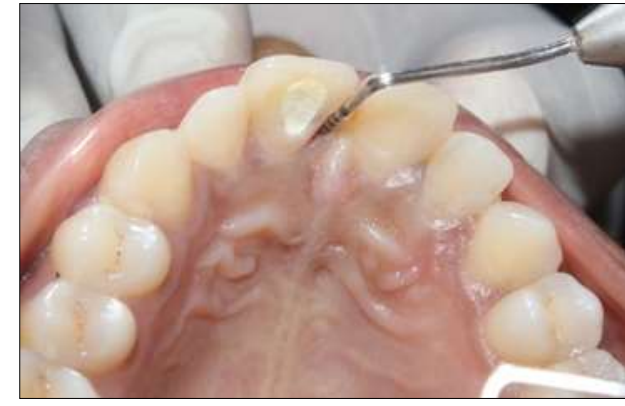

Fig 1: Pre-operative pocket depth of $11 \mathrm{~mm}$ irt. Mesio-Facial and Mesio-Palatal aspect of 21.

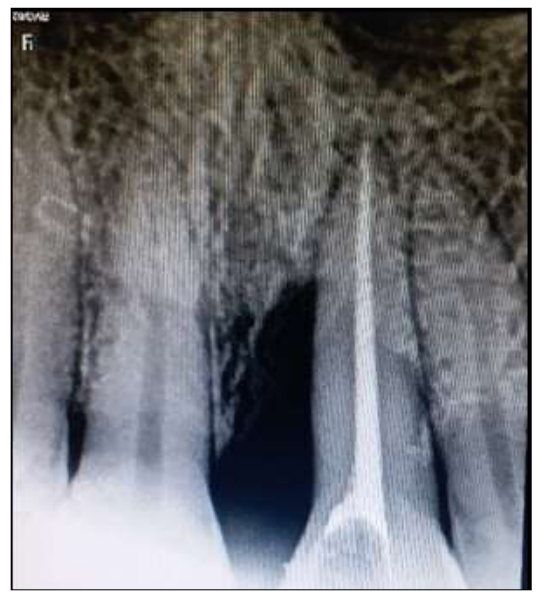

Fig. 2 IOPA irt. 21
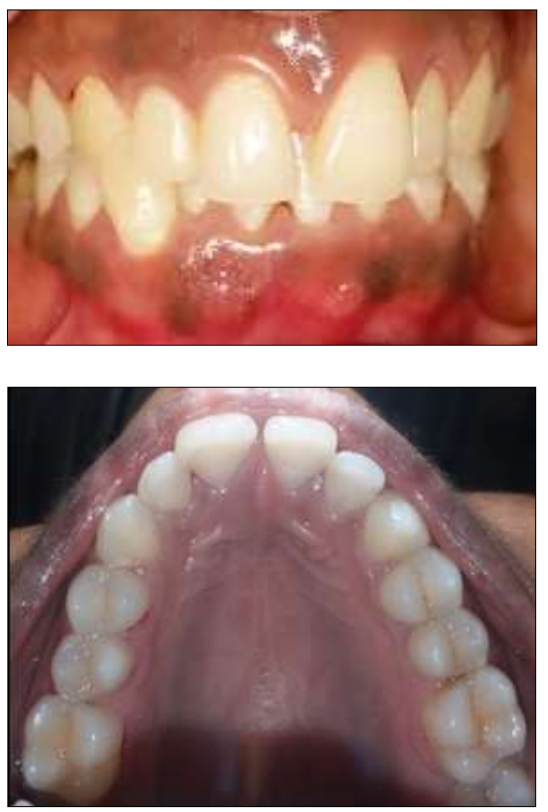

Fig 3: Post Phase I Therapy

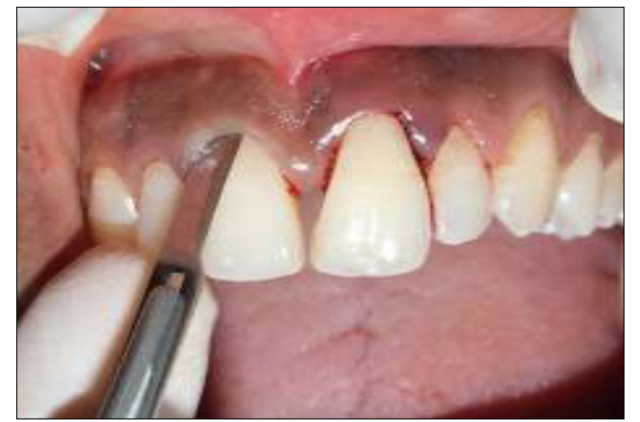




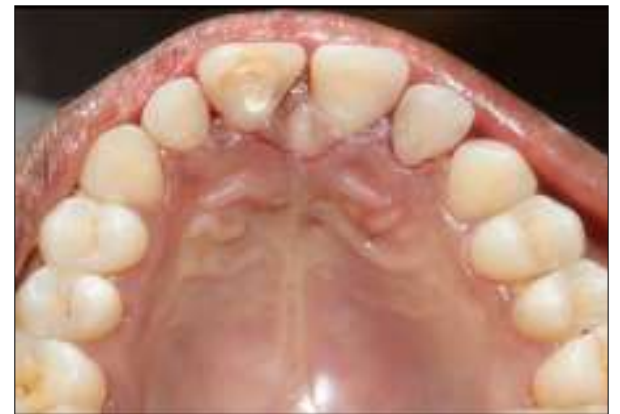

Fig 4: Crevicular and Papilla Preservation Incisions Placed.
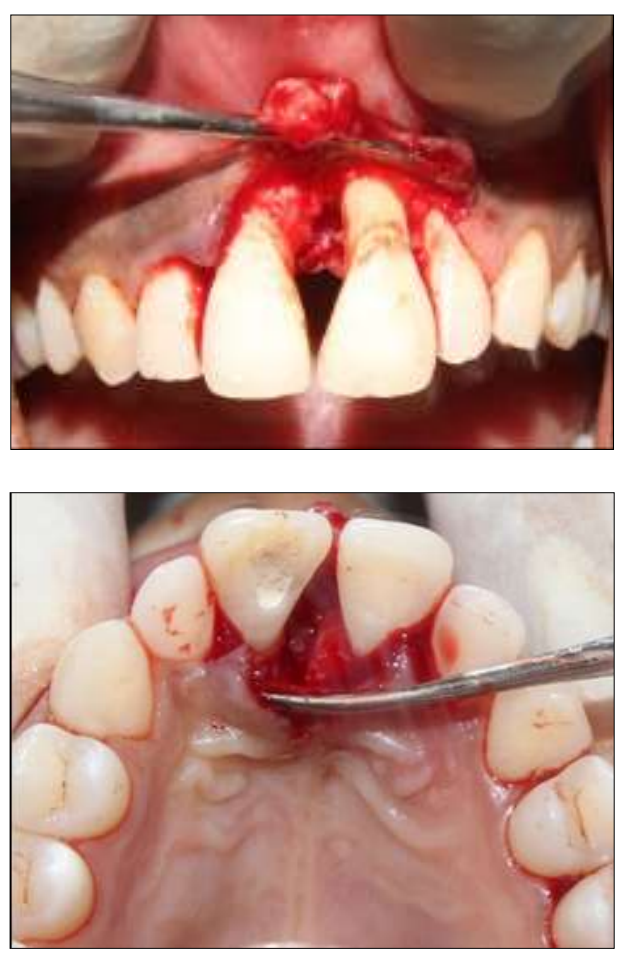

Fig. 5 Full Thickness Flap Raised on Facial and Palatal Aspect

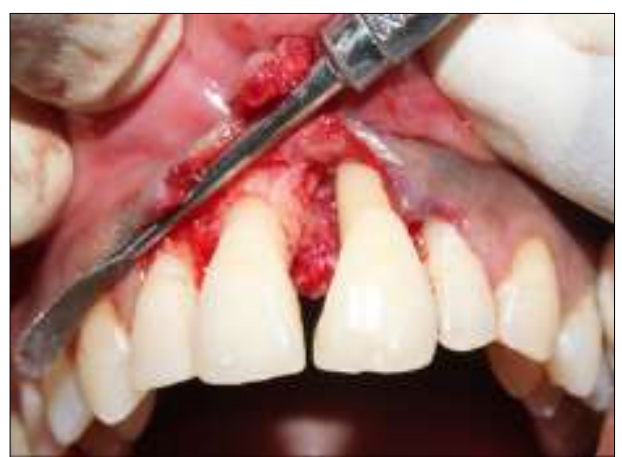

Fig 6: Debridement of the defect

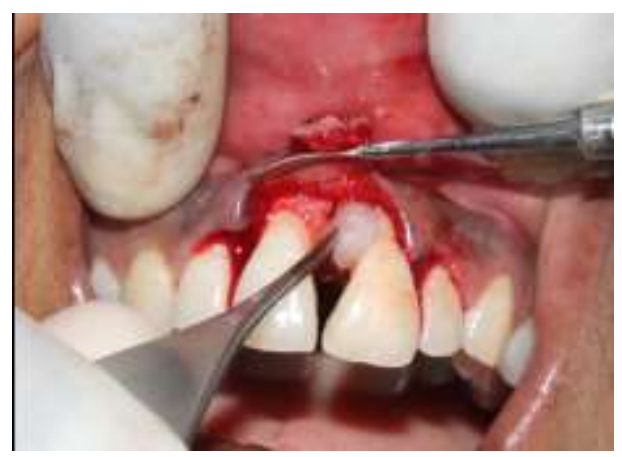

Fig 7: Root biomodification done
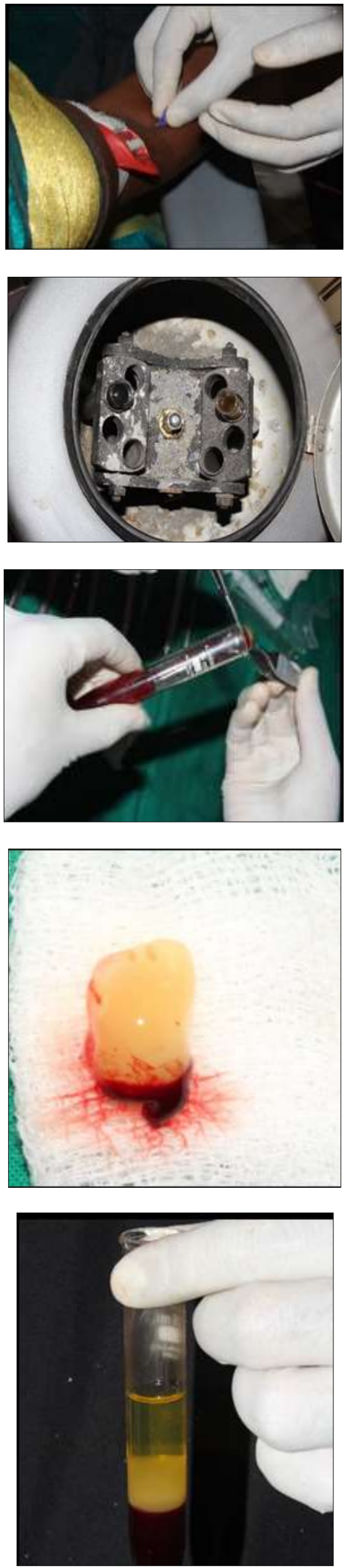

Fig 8: Platelet Rich Fibrin Preparation 

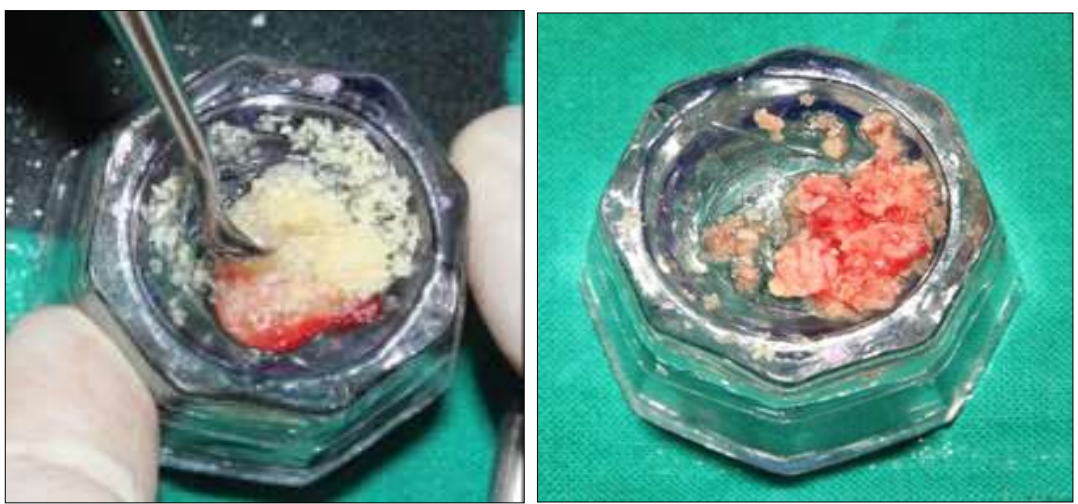

Fig 9: PRF mixed with bone graft to prepare into a transferable mass
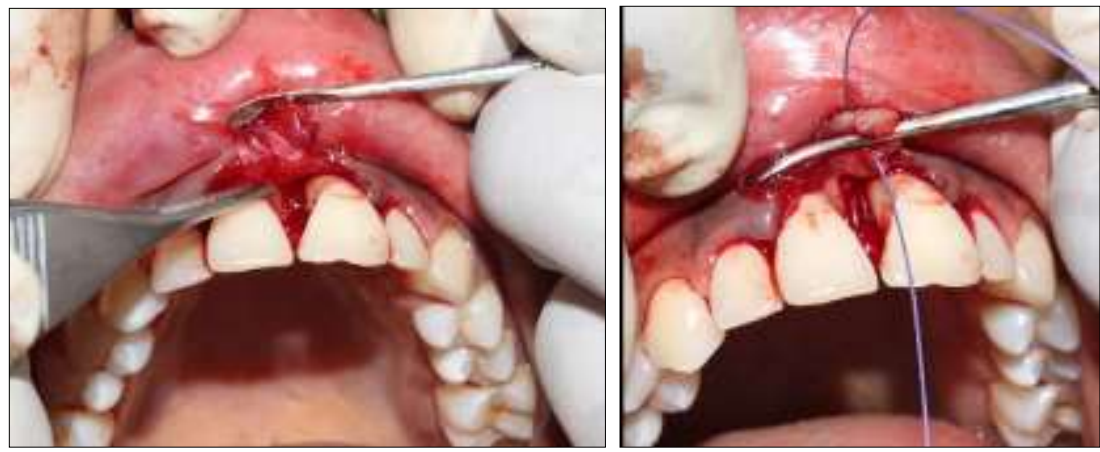

Fig 10: Barrier Membrane Adapted and Pre-Suturing Done
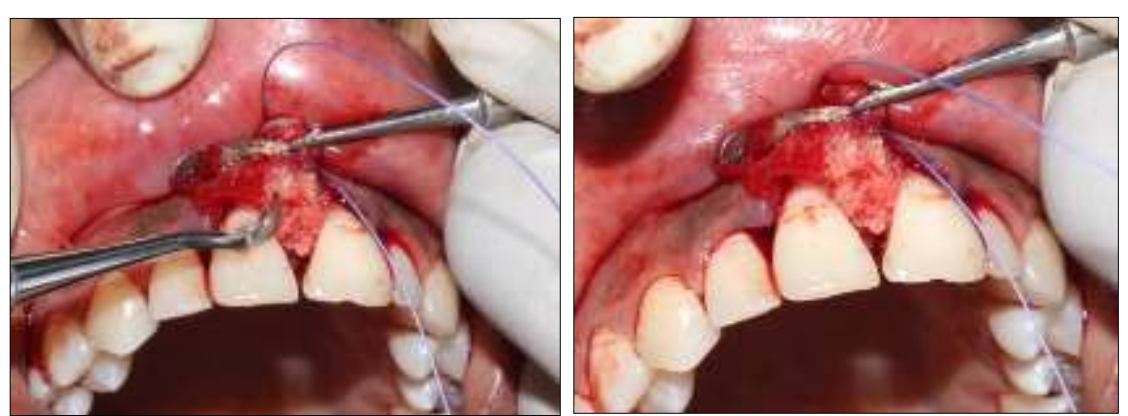

Fig 11: Transferable Mass Placed
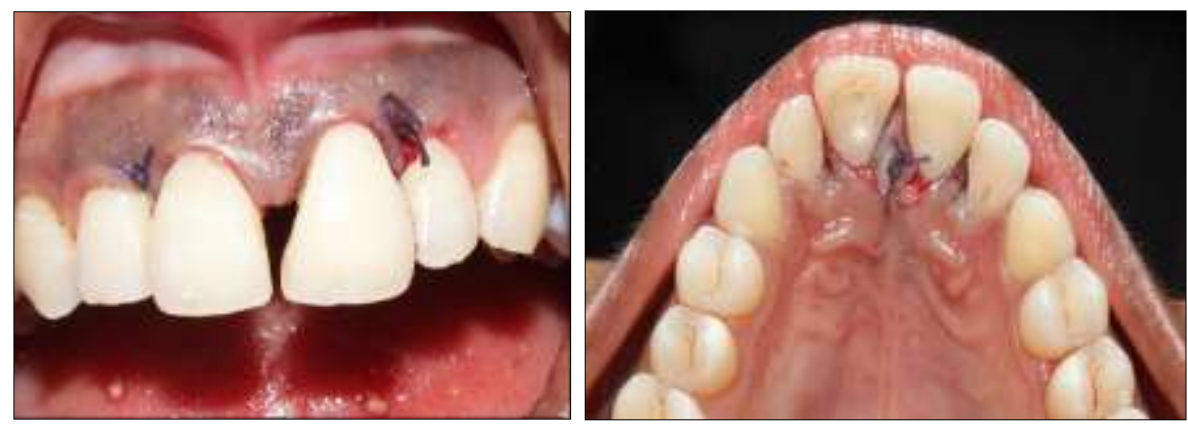

Fig 12: Flap secured with resorbable suture
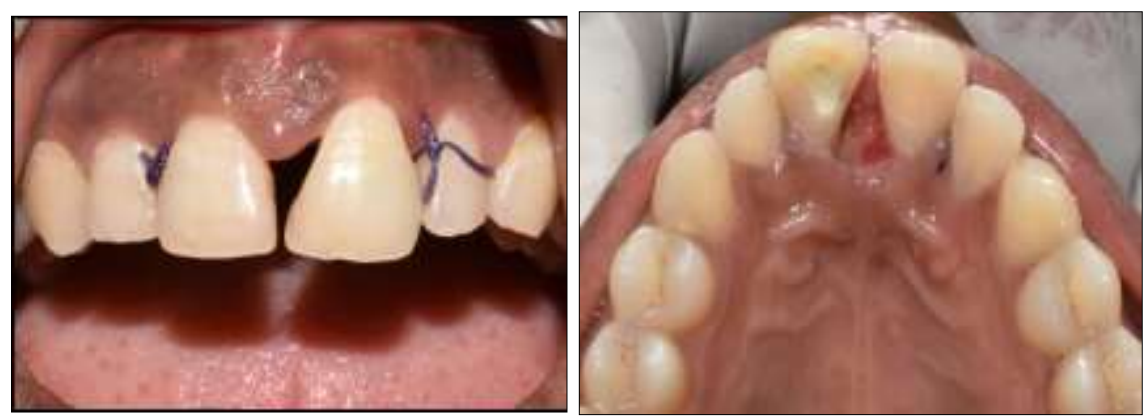

Fig 13: 1 Week Post-Operative Photograph 


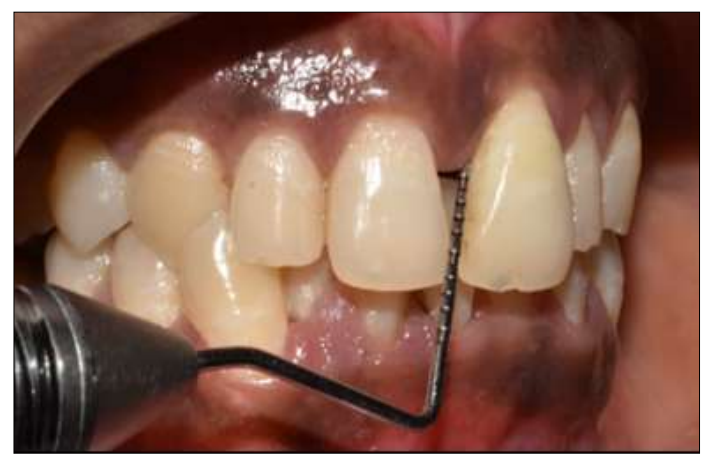

Fig 14: 6 Month Post-Operative Photograph
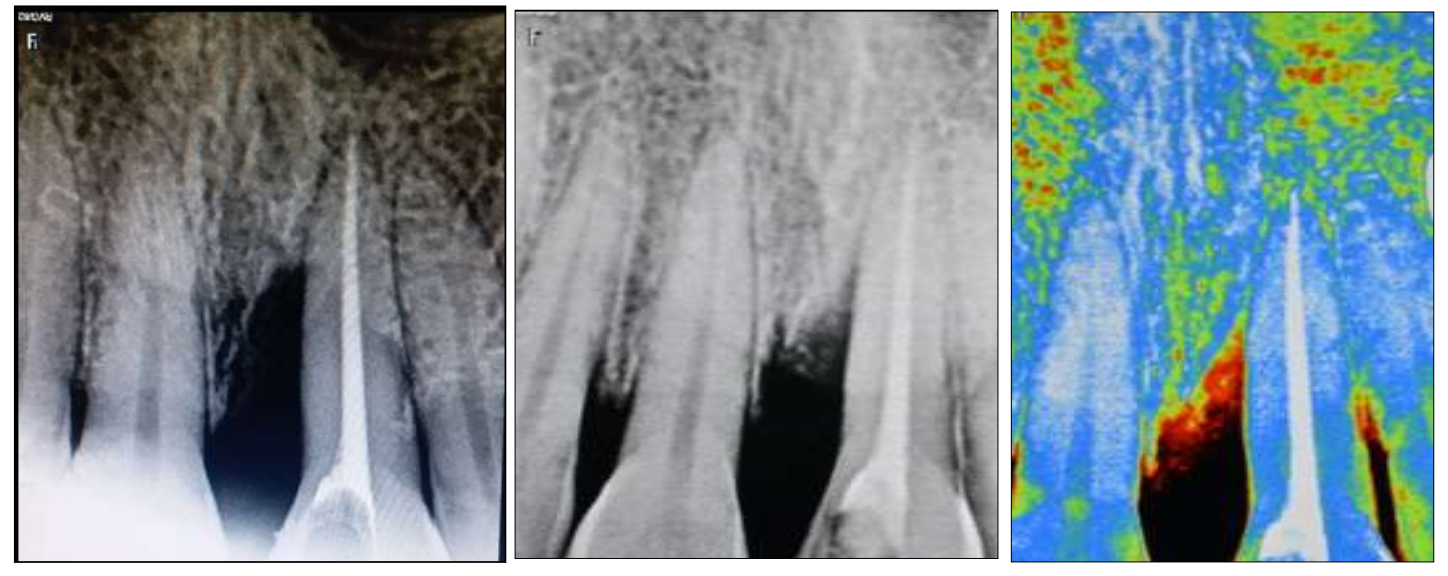

Fig 15: 6 Month Post-Operative Radiograph

\section{Discussion}

The ultimate goal for periodontal treatment is to reconstitute the lost bone and connective tissue attachment. ${ }^{14}$ Conventional periodontal therapy fails to regenerate the periodontium because of differences in the healing abilities among periodontal tissues. In the last few years, great research has been carried out to invent techniques that can achieve complete regeneration of the lost periodontium. This had led to introduction and application of a variety of treatment modalities for this intent, but only a few have been seen to be successful.

The present case report aimed to evaluate the integrated efficacy of Platelet Rich Fibrin and DFDBA in the treatment of infrabony defects in patients with chronic periodontitis and showed a significant improvement in clinical and radiographic parameters. Blumenthal NM et al. ${ }^{[15]}$ conducted a study to compare regenerative outcomes in baboon with intrabony defects that were contained versus non-contained, using various regenerative therapies. For contained defects no significant clinical or histological differences existed between treatments. However, for non-contained defects, combined therapy (collagen membrane + DFDBA) exhibited clinically significant and histologically superior healing results over other treatment modalities ${ }^{[15]}$.

The physical properties of PRF make it feasible to be used in combination with a variety of bone grafts. Advantages of such a combination include promoting wound healing, bone growth and maturation, graft stabilization and hemostasis, and also it improves the handling properties of graft material. Sunitha $\mathrm{R}$ V. in 2008 stated that, when concentrated growth factors in the form of PRF are added to graft materials, a more predictable outcome can be achieved ${ }^{[16]}$. PRF contains numerous growth factors out of which PDGF and TGF- $\beta$ are of prime importance when regeneration is considered [16]. They help in the protein synthesis in osseous tissues, stimulates angiogenesis, and enhance woven bone formation, etc. ${ }^{[16]}$

On the other hand, DFDBA has been widely used for periodontal regenerative procedures for years together. It is known to have an osteoconductive as well as osteoinductive potential that leads to exposure of bone morphogenetic protein (BMPs) which presumably have the ability to induce host cells to differentiate into osteoblast. They have been successfully used to reconstruct intraosseous periodontal defects.

Mellonig et al. in $1987^{[17]}$ conducted a study to evaluate the regenerative potential of DFDBA in human periodontal defects. Subjects in test group were treated with DFDBA after thorough open flap debridement and those in control group were treated with open-flap debridement only. All defects were evaluated after 6 months postoperatively. Surgical reentry disclosed that there was $64.7 \%$ of bone fill in the sites which were treated with DFDBA. It was concluded that DFDBA has definite potential as a graft material in periodontal regenerative therapy ${ }^{[17]}$.

Simonpieri et al. in $2009^{[18]}$ evaluated the efficacy and advantages of the use of PRF during bone grafting. They found that firstly, the fibrin clot plays an crucial role in maintaining and stabilizing the graft material and serves as a biological adhesive for particulate graft material. Secondly, fibrin meshwork present in PRF facilitates cellular migration, vascularization, and survival of the graft. Thirdly, the growth factors PDGF, TGF- $\beta$, IGF- 1 are gradually released as the fibrin matrix is resorbed, thus creating a perpetual process of healing. Lastly, the presence of leukocytes and cytokines in the fibrin network play an important role in the self-regulation of inflammatory response within the grafted material.

In more recent past, numerous studies have been conducted by combining PRF with DFDBA in the treatment of periodontal defects. Bansal et al. in $2013^{[19]}$ and Khattar et al. 
in $2014^{[20]}$ conducted a study to evaluate the efficacy of autologous PRF with the DFDBA, in the treatment of periodontal intrabony defects. Bothe the authors concluded that this combination approach towards treatment of periodontal intrabony defects demonstrated significant improvement in the clinical as well as radiographic parameters.

Findings of the present case report are in accordance with those of Bansal et al. in $2013^{[19]}$ and Khattar et al. in 2014 [20]. The application of PRF in periodontal regeneration had two major benefits: (i) the promotion of soft tissue healing (ii) the induction of new alveolar bone formation ${ }^{[21]}$. Soft tissue healing was uneventful at first week as well as subsequent follow ups. In this case report, we used DFDBA of 450 microns particulate size and achieved a linear bone fill of 3$4 \mathrm{~mm}$ checked on RVG with gain in CAL and reduction in probing depth from $11 \mathrm{~mm}$ to $4 \mathrm{~mm}$, at 6 month follow up.

\section{Conclusion}

From the presented case report, it can be concluded that a combined approach PRF and DFDBA is effective in the treatment of periodontal intrabony defects. PRF is an autologous preparation derived from patients own blood. Hence it is not only clinically effective, but also economical and can be used in the treatment of periodontal intrabony defects.

\section{References}

1. American Academy of Periodontology. Glossary of periodontal terms, 3rd edn. Chicago: American Academy of periodontology, 1992.

2. Bender SA, Rogalski JB, Mills MP, Arnold RM, Cochran DL, Mellonig JT. Evaluation of demineralized bone matrix paste and putty in periodontal intraosseous defects. J Periodontol 2005;76:768-77.

3. Rosen PS, Raynolds M, Bowers G. The treatment of intrabony defects with bone grafts. Perio 2000;22:88103.

4. Ross R, Glomset J, Kariya B, Harker L. A plateletdependent serum factor that stimulates the proliferation of arterial smooth muscle cells in vitro. Proc Natl Acad Sci U S A 1974;71:1207-10.

5. Kiran NK, Mukunda KS, Tilak Raj TN. Platelet concentrates: A promising innovation in dentistry. J Dent Sci Res 2011;2:50-61.

6. Choukroun J, Adda F, Schoeffler C, Vervelle A. Une opportunité en paro-implantologie: le PRF. Implantodontie 2000;42:55-62.

7. Dohan DM, Choukroun J, Diss A, Dohan SL, Dohan AJ, Mouhyi J, et al. Platelet-rich fibrin (PRF): a secondgeneration platelet concentrate. Part I: technological concepts and evolution. Oral Surg Oral Med Oral Pathol Oral Radiol Endod 2006;101:e37-44.

8. Saluja H, Dehane V, Mahindra U. Platelet Rich fibrin: A second generation platelet concentrate and a new friend of oral and maxillofacial surgeons. Ann Maxillofac Surg 2011;1:53-7.

9. Bölükbaşı N, Ersanlı S, Keklikoğlu N, Başeğmez C, Ozdemir T. Sinus augmentation with platelet-rich fibrin in combination with bovine bone graft versus bovine bone graft in combination with collagen membrane. J Oral Implantol 2013. [Epub ahead of print].

10. Joseph VR, Sam G, Amol NV. Clinical evaluation of autologous platelet rich fibrin in horizontal alveolar bony defects. J Clin Diagn Res 2014;8:43-7.
11. Kim TH, Kim SH, Sándor GK, Kim YD. Comparison of platelet-rich plasma (PRP), plateletrich fibrin (PRF), and concentrated growth factor (CGF) in rabbit-skull defect healing. Arch Oral Biol 2014;59:550-8.

12. Wu CL, Lee SS, Tsai CH, Lu KH, Zhao JH, Chang YC. Platelet-rich fibrin increases cell attachment, proliferation and collagen-related protein expression of human osteoblasts. Aust Dent J 2012;57:207-12.

13. Dohan Ehrenfest DM, Diss A, Odin G, Doglioli P, Hippolyte MP, Charrier JB. In vitro effects of Choukroun's PRF (platelet-rich fibrin) on human gingival fibroblasts, dermal prekeratinocytes, preadipocytes, and maxillofacial osteoblasts in primary cultures. Oral Surg Oral Med Oral Pathol Oral Radiol Endod 2009;108:341-52.

14. Zander HA, Polson AM, Heijl LC. Goals of periodontal therapy. J Periodontol 1976; 47:261-6.

15. Blumenthal NM, Alves ME, Al-Huwais S, Hoß auer AM, Koperski RD. Defect Determined regenerative options for treating periodontal intrabony defects in Baboons. J Periodontol 2003;74:10-24.

16. Sunitha Raja V, Munirathnam Naidu E. Platelet rich fibrin: Evolution of a second generation platelet concentration. Indian J Dent Res 2008;19:42-6.

17. Mellonig JT. Decalcified freeze-dried bone allograft as an implant material in human periodontal defects. Int $\mathbf{J}$ Periodontics Restorative Dent 1984;4:40-55.

18. Simonpieri A, Del Corso M, Sammartino G, Dohan Ehrenfest DM. The relevance of choukroun's plateletrich fi brin and metronidazole during complex maxillary rehabilitations using bone allograft. Part II: Implant Surgery, prosthodontics and survival. Implant Dent 2009;18:220-9.

19. Bansal C, Bharti V. Evaluation of autologous platelet rich fibrin with the demineralized freeze dried bone allograft in the treatment of periodontal intrabony defects. J Indian Soc Periodontol 2013;17:361-6.

20. Khattar S, Kaushik M, Tomar N. The use of platelet rich fibrinand demineralized freeze dried bone allograft in the treatment of intrabony defect-A case report. Sch J Med Case Rep 2014;2:563-7.

21. Chang YC, Zhao JH. Effects of platelet-rich fibrin on human periodontal ligament fibroblasts and application for periodontal infra-bony defects. Australian Dental Journal 2011;56(4):365-371. 